\title{
TÉCNICA E TECNOLOGIA PRESENTES NAS OBRAS DE LEONARDO DA VINCI NO PERÍODO RENASCENTISTA: UMA ABORDAGEM DE CIÊNCIA E PEDAGOGIA HISTÓRICO-CRÍTICA POR MEIO DE SEQUÊNCIA DIDÁTICA
}

\author{
Adriane Gonçalves Gomes ${ }^{1}$, Carlos Roberto Pires Campos ${ }^{2}$ \\ Programa de Pós-graduação em Educação em Ciências e Matemática \\ Instituto Federal do Espírito Santo - Campus Vitória \\ Avenida Vitória, 1729 - Jucutuquara, Vitória, Espírito Santo. CEP 29040780.
}

\begin{abstract}
RESUMO
0 artigo resulta de uma proposta de sequência didática interdisciplinar que aborda temas da história em interface com a ciência, organizada nos três momentos pedagógicos, tendo por intuito apresentar, de maneira diferenciada e lúdica, a temática Tecnologia e Técnica no Período Renascentista com enfoque nas criações de Leonardo da Vinci, tais como suas obras de arte e invenções, no intento de promover a alfabetização científica por meio de abordagem temática com incursões da pedagogia histórico-crítica, buscando não apenas despertar a curiosidade dos discentes para os temas trabalhados bem como enfatizar tais temas, levando em consideração o complexo histórico-social dos quais estes emergiram.
\end{abstract}

Palavras-chave: alfabetização científica, sequência didática, pedagogia histórico-crítica.

\begin{abstract}
This article results from a proposal of a interdisciplinary teaching sequence that addresses issues of history in interface with science, organized in three pedagogical moments, with the aim to present differently and ludically the theme Technology and Technique in the Renaissance period with a focus in some creations of Leonardo da Vinci works of art as well as some inventions of his with the intent to promote scientific literacy through a thematic approach to incursions of historical-critical pedagogy, seeking not only to arouse the curiosity of students to the themes discussed but emphasize such issues taking into account the complex historical and social which these emerged.
\end{abstract}

Keywords: scientific literacy, didactic sequence, historical-critical pedagogy.

1 Professora de História, Mestre em Educação em Ciências e Matemática. E-mail: adrianegoncalvesgomes@yahoo.com.br

2 Professor de Língua Portuguesa, Doutor em História Social da Cultura. Docente do Programa de Pós-graduação em Educação em Ciências e Matemática do Instituto Federal do Espírito Santo. E-mail: carlosr@ifes.edu.br

Revista Eletrônica Debates em Educação Científica e Tecnológica, ISSN: 2236-2150 - V. 2, N. 02, p. 59 - 67, Dezembro, 2012 


\section{INTRODUÇÃO}

O tema ciência e tecnologia, e sua relação com o papel da educação na construção do pensamento científico, tem alcançado notório destaque e auferiu, no atual cenário mundial, de busca por uma alfabetização científica, feições que nos remete à impossibilidade de dissociar uma da outra. Segundo Freire (1996), alfabetizar vai muito além de ler letras, deve proporcionar a "Leitura de Mundo", isso significa que o ensino conteudista, que não favorece a construção reflexiva dos conceitos trabalhados com os alunos, faz com que estes não relacionem conteúdo e realidade. Dessa perspectiva, o processo passa a ser pouco significativo, tornando os discentes meros expectadores ao conteúdo curricular.

A presente sequência didática de caráter interdisciplinar abordou temas referentes ao ensino de história com relação à técnica e à tecnologia em interfaces com o ensino de ciência. A intenção foi sugerir que tal proposta pedagógica fosse executada com alunos de ensino médio; chegamos a essa conclusão a partir das necessidades dos alunos as quais foram observadas no decorrer de nossa práxis de se trabalhar o conteúdo curricular em consonância com a realidade dos discentes. Isso, com o intuito de formar uma população mais crítica, capaz de ser atuante e compreender o complexo do mundo atual, onde as informações e os variados saberes encontram-se presentes e disponíveis na sociedade.

A inteligência parcelada, compartimentada, mecanicista, disjuntiva e reducionista rompe o complexo do mundo em fragmentos disjuntos, fraciona os problemas, separa o que está unido, torna unidimensional o multidimensional. É uma inteligência míope que acaba por ser normalmente cega. (MORIN, 2002, p.40).

Segundo Delizoicov et al. (2011, p.54), é preciso mais objetividade com relação aos conceitos, uma mudança na maneira de ensinar, e no que ensinar nas escolas, para que os discentes passem de uma visão fragmentária para uma mais ampla, que os possibilitem a se perceberem como sujeitos integrados ao meio ambiente e à sociedade, estando cientes da necessidade de uma atuação consciente e comprometida sobre estes. Para que essa mudança ocorra, a escola necessita repensar seu papel enquanto formadora de opinião e se assumir, como fundamental, na construção do conhecimento científico. Para os autores, a escola precisa proporcionar uma formação que possibilite aos discentes o exercício da cidadania e os prepare para enfrentar os desafios cotidianos seja esses na área das ciências naturais ou tantas outras. 
De acordo com Teixeira (2003, p.179), a Pedagogia Histórico - Crítica e o Movimento C.T.S no ensino de ciências podem contribuir de forma significativa para o (re)direcionamento da educação científica da atualidade. 0 autor faz crítica ao fato de o ensino de ciências ser marcado por um conteudismo, que pouco favorece a interação do aluno com os temas apresentados. E os alunos não contemplando o desenrolar do progresso científico, não conseguirão compreender os meios pelos quais determinados cientistas chegaram a descobertas que influenciam sua vida cotidiana. Não são apresentados na escola os meios que despertaram nesse cientista a necessidade de criar determinada teoria ou inovação tecnológica; a visão apresentada não condiz com a realidade, tendo como consequência uma formação superficial por parte dos alunos, que não alcançam, com esse processo de ensino aprendizagem, a amplitude de um determinado processo científico. Ocorre que os alunos acabam por conhecer somente o produto final da ciência, sem levar em conta todos os caminhos culturais, barreiras ideológicas e desafios do processo até o seu fim. Essa proposta de se inteirar do processo através do qual o conhecimento foi produzido dialoga com o que nos leciona Durant (2005, p.22) para quem a alfabetização científica seria o que o público em geral deveria saber a respeito da ciência, e a difusão do seu uso reflete uma preocupação acerca do desempenho dos sistemas educacionais vigentes. Para Chassot (2003, p.42), a alfabetização científica pode ser considerada como uma das dimensões para potencializar uma educação mais comprometida.

Intentamos, com essa sequência, avançar para um ensino que valorize o complexo, com intenção de atentar para a necessidade de nos interrogarmos com relação à postura científica, que se torna reflexo da sociedade, fragmentada e desconectada com o valor subjetivo inerente ao ser humano, bem como de que maneira a própria ciência intensifica, por meio dessa postura, os problemas da fragmentação da sociedade em seus mais variados setores. Para o desenvolvimento de tal ação pedagógica, usamos o modelo de sequência didática de acordo com Delizoicov (1992) no intuito de articular os conhecimentos básicos (três saberes) chamados pelo autor (DELIZOICOV et al. 2011., p. 201) de três momentos pedagógicos (3 MP) quais sejam: Problematização do tema (P), organização do conhecimento(O) e aplicação do conhecimento (A). 0 objetivo deste trabalho foi abordar, a partir de uma sequência didática pautada nos 3MP, um ensino que caminhe em direção à alfabetização científica, levando em conta o complexo da sociedade contemporânea, na busca de formar cidadãos críticos hábeis para intervirem na sociedade, com consciência e capacidade de questionamento. 


\section{PROCEDIMENTOS METODOLÓGICOS}

Esta sequência didática possui característica pautada em uma natureza qualitativa, tendo sido elaborada a partir do método dos três momentos pedagógicos propostos por Delizoicov et al. (2011). Nossa análise foi feita a partir de aspectos históricos e filosóficos com algumas incursões do método sociológico, a análise dos conteúdos foi baseada em Bardin (2004). 0 público alvo foram alunos do segundo ano do Ensino Médio, e para a execução desta seqüência, programamos um tempo estimado em cinco semanas ( 15 aulas) como consta na Tabela 1.

No primeiro momento pedagógico da problematização, o docente deverá estimular a participação dos alunos, para que esses apresentem a visão que possuíam do assunto. Nesse momento, espera-se do professor ações no intuito de estabelecer conexões dos conteúdos propostos com o cotidiano dos alunos, instigando-os a perceberem se, de alguma forma, existe influência dos avanços tecnológicos e das técnicas no seu cotidiano, permitindo-lhes expressarem, a sua visão sobre a arte e invenções, questionando-os, ainda, se se identificam, como parte ou não, de tais avanços científicos e se já se imaginaram, de alguma forma, como protagonistas de tais inventos. Após esse momento inicial, em sala de aula, os alunos foram encaminhados ao laboratório de informática para iniciarem pesquisa sobre o tema, a fim de produzirem texto com resultados da pesquisa como deverá ser sugerido pelo professor, como consta, acima, no primeiro momento pedagógico da problematização.

No segundo momento, intitulado Organização do conhecimento, o docente apresenta o novo conteúdo aos alunos, utilizando os exemplos apresentados pelos mesmos nas aulas anteriores, no intuito de promover-lhes uma aprendizagem mais significativa, nesse momento o professor poderá apresentar, trecho de vídeos retirados do You Tube (http://youtu.be/Yb_ThnyNTM trecho do filme sobre invenções de Leonardo da Vinci, sugerimos os 6 primeiros minutos desse vídeo, que permite perceber a evolução da tecnologia na Itália renascentista com as invenções de Da Vinci, na engenharia militar, maquinarias, moinhos, bombas e aparelhos hidráulicos, máquina têxtil, peças de artilharia, objetos de metal, máquina de polir e até um aparelho para voar). 
Tabela 1. Breve descrição dos Momentos Pedagógicos

\begin{tabular}{|c|c|c|}
\hline AULAS & $\begin{array}{l}\text { MOMENTOS } \\
\text { PEDAGÓGICOS }\end{array}$ & ATIVIDADES PROPOSTAS \\
\hline \multirow{3}{*}{$1 \underline{a}$ à $5 \underline{a}$} & \multirow{3}{*}{$P$} & $\begin{array}{l}\text { Apresentar a proposta de trabalho e discutir com os alunos os meios de } \\
\text { pesquisa, os estimulando a interagir através dos conhecimentos prévios que } \\
\text { esses possuem sobre o tema. }\end{array}$ \\
\hline & & $\begin{array}{l}\text { Pedir para que os alunos pesquisem em sites e livros, informações sobre o } \\
\text { renascimento cultural e como as obras de Da Vinci refletem esse contexto, } \\
\text { pedir para que pesquisem e relacionem as inovações das técnicas e da } \\
\text { tecnologia, do período medieval para o moderno com foco nas artes e nas } \\
\text { armas, bem como nos instrumentos de produção agrícolas. }\end{array}$ \\
\hline & & $\begin{array}{l}\text { Orientar os alunos a focar a pesquisa na personalidade de Leonardo da Vinci } \\
\text { enquanto pintor e inventor sempre analisando o reflexo do contexto } \\
\text { histórico em suas obras, e a presença dos vários conhecimentos que esse } \\
\text { usava para suas criações. Produção de texto com os resultados da pesquisa } \\
\text { apresentados em discussão na aula, bem como suporte para a participação } \\
\text { desses ao longo das aulas seguintes. }\end{array}$ \\
\hline \multirow{3}{*}{$6^{\mathrm{a}} \mathrm{à} 10^{\underline{a}}$} & \multirow{3}{*}{0} & $\begin{array}{l}\text { Aula expositiva dialogada com apresentação dos principais conceitos do } \\
\text { Período Renascentista, quais sejam: racionalidade geocêntrica, humanismo, } \\
\text { antropocentrismo, valorização da estética artística com forte influência do } \\
\text { clássico greco-romano e a busca do conhecimento em várias áreas. Recursos } \\
\text { (slides) com obras de arte do autor e pequenos vídeos retirados do you tube } \\
\text { sobre vida e obra de Leonardo Da Vinci. }\end{array}$ \\
\hline & & $\begin{array}{l}\text { - Discussão a partir das investigações feitas pelos alunos sobre os avanços } \\
\text { no campo da técnica e da tecnologia, em especial nas artes e invenções } \\
\text { (debate mediado pelo professor). } \\
\text { - Busca do entendimento de mundo a partir das várias ciências, quais sejam, } \\
\text { História, química, matemática, física e ciências, fundamentais e utilizadas } \\
\text { por Leonardo Da Vinci em suas criações, no intuito de despertar a } \\
\text { criticidade dos alunos para a percepção dos vários saberes presentes nos } \\
\text { feitos de Da Vinci. }\end{array}$ \\
\hline & & $\begin{array}{l}\text { - Destacar a personalidade cientifica de Leonardo da Vinci e suas criações } \\
\text { nas variadas áreas, sendo ele: engenheiro, matemático músico, naturalista, } \\
\text { inventor e escultor. }\end{array}$ \\
\hline \multirow{3}{*}{$\begin{array}{c}11^{\mathrm{a}} \mathrm{e} \\
15^{\underline{a}}\end{array}$} & \multirow{3}{*}{ A } & $\begin{array}{l}\text { Proposta } 1 \text { - Apresentação da proposta desenvolvida pelos alunos de } \\
\text { invenções feita pelos mesmos, onde esses trabalharam com duas ou mais } \\
\text { áreas do saber ( atividade em grupo ). }\end{array}$ \\
\hline & & $\begin{array}{l}\text { Proposta } 2 \text { - Analise de exposições que envolvam ciência, arte ou tecnologia } \\
\text { apresentando as varias ciências presentes nessa. Exposição oral em forma } \\
\text { de banners em sala de aula ou apresentação em slides em auditório aberta } \\
\text { para visitação das outras turmas da escola. }\end{array}$ \\
\hline & & $\begin{array}{l}\text { A proposta } 1 \text { e } 2 \text { terão culminância em exposição, feita na escola na sala de } \\
\text { aula e aberta a visitação de outros alunos dessa instituição de ensino. }\end{array}$ \\
\hline
\end{tabular}


Além disso, sugerimos, nesse momento, outro vídeo retirado do You Tube http://youtu.be/RI5MN6NtYA que aborda as obras de arte com enfoque nas principais características das pinturas de Da Vinci quais sejam: utilização de técnica artística da perspectiva, as cores próximas a realidade, flagrante do momento de tensão muscular e do movimento do corpo etc. Busca-se trabalhar com tais vídeos de maneira lúdica, apresentando e discutindo com os alunos temas da ciência, seus benefícios e consequências, fazendo-os atentarem para a responsabilidade social que permeia as nossas ações, enquanto sujeitos sociais, que detêm meios de intervenção na natureza, buscando despertar nesses, a visão de que, com tais tecnologias e benefícios, vem, também, a necessidade de cautela e responsabilidade com o ambiente. Enfocamos aqui o desenvolvimento das técnicas e das tecnologias, e como essas surtem em consequências positivas e negativas para a humanidade.

A partir desse momento, focamos nossa atenção na exibição de slides, com imagens que visaram a proporcionar um processo de assimilação de modo mais lúdico para os alunos, no intento de estabelecer relações do conteúdo curricular com sua realidade. No que se refere à avaliação, acreditamos que esta se faz desde o primeiro momento, configurando-se como um processo de construção, portanto os alunos devem ser avaliados em sua íntegra, ou seja, durante cada etapa do processo. Os alunos foram estimulados de diversas maneiras, desde debates a exercícios que enfocaram as características e influências perceptíveis, dos conteúdos estudados em sala, com o cotidiano dos discentes, levando-se em conta o que consta do Quadro 1.

Quadro 1: Conteúdos abordados na sequência didática.

- Renascimento cultural e científico;

- Racionalidade, realismo na apresentação de objetos pessoas e paisagens, mecenato;

- Humanismo, antropocentrismo;

- Valorização da estética artística com forte influência Greco - romana e a busca do conhecimento em várias áreas;

- Surgimento de novos meios de comunicação, surgimento das academias;

- Geocentrismo e heliocentrismo;

- Obras de arte e suas principais características;

- Técnica e Tecnologias nas artes e nas invenções;

O terceiro momento pedagógico configura-se como mais propício para a aplicação do conhecimento. 0 intento será articular o conhecimento científico a situações reais significativas, em que os alunos terão a oportunidade de colocar em prática os novos 
conceitos adquiridos. Ressaltamos que, durante todo o processo, os alunos foram avaliados, todavia deixamos a avaliação de maior valor quantitativo para culminância de tal sequência, em uma exposição, realizada pelos alunos com mediação do professor, dentro da instituição escolar e aberta à visitação de outras turmas da mesma instituição.

Nesse momento, sugerimos aos alunos duas propostas de avaliação as quais os discentes escolheram uma para realizar, a primeira se tratou da reconstrução ou criação de algum mecanismo ou instrumento em que esses utilizassem mais de uma área do saber como ciência e história para sua criação, para que esse fosse exposto como resultado do processo avaliativo, tal invento poderia ser uma réplica dos que foram apresentados em sala ou algo original que tivesse utilidade e de alguma forma facilitasse alguma atividade cotidiana dos discentes. A segunda proposta avaliativa tratou da análise de exposições (o grupo de alunos, a partir de pesquisas, deveria escolher uma exposição que já tenha acontecido, e pudesse adaptar-se a situações que estes vivenciam cotidianamente, para que percebam a proximidade da ciência com sua realidade), o intento, aqui, além de promover a alfabetização científica, a criticidade dos alunos e a aplicação do conhecimento perante aos temas estudados, visa, ainda, à promoção da divulgação científica tema pouco abordado em nossas escolas.

Durante os últimos anos, houve uma onda internacional de preocupação com as relações entre ciência e a cultura em geral. Todos nós, cientistas e professores, autores e radiodifusores, curadores de museus e monitores de centros de ciência. Mas, na verdade, o que todas essas pessoas estão tentando alcançar? 0 que querem dizer com "compreensão pública da ciência”, na Inglaterra; com "cultura científica", na França; com "alfabetização científica”, nos Estados Unidos?.(DURANT, 2005. P.14)

Defendemos a alfabetização científica como a busca pelo conhecimento científico, o acesso, bem como, o uso consciente dos meios de divulgação científica, como agentes somatizadores no processo de colocar a educação e, consequentemente, os alunos e até a comunidade escolar no "páreo" do mundo atual. 0 cidadão que pretendemos, e precisamos, formar, hoje, não se satisfaz mais com conteúdos repetidos e decorados de livros didáticos. Observamos, em nossas salas de aula, a mudança diária do foco do conhecimento, a ciência, mesmo que ainda não seja trabalhada como tema presente na vida de nossos alunos, já é parte atuante na construção da identidade desses, ainda que os tais não tenham conhecimento de tal fato. Enfatizamos, ainda, que, durante o desenrolar de tal sequência, os alunos possuíram diversas 
oportunidades de interagir e apresentar seus conhecimentos prévios, tornando, assim, tal processo de ensino-aprendizagem mais significativo, ancorando seus conhecimentos novos naqueles decorrentes de sua práxis social e humana, em outras palavras, em seu acervo cognitivo e cultural. A realização da exposição a qual sugerimos se configura como mais um adicionante nesse processo, onde os discentes tiveram a oportunidade de explicar seu ponto de vista, perante os conteúdos trabalhados, e como estes são presentes e passíveis de aplicação em sua realidade.

\section{CONSIDERAÇÕES FINAIS}

Julgamos que trabalhar com o tema de técnica e tecnologia, por meio de sequência didática baseada nos 3MP, favorece que o aluno consiga construir de forma mais significativa alguns conceitos considerados abstratos, como os temas do renascimento cultural e científico. Buscou-se abordar tais temas, com vias à alfabetização científica, sempre atentando para as consequências dos avanços tecnológicos, trabalhando a interface entre ciência, contexto histórico e responsabilidade social, em consonância com a pedagogia histórico-crítica.

Entendemos tal sequência, o uso de novas metodologias entre outras práticas, que envolvam atividades lúdicas e situações problematizadoras, como somatizadores no intento de buscar um ensino que vise a superar o propedêutico, estimulando o despertar dos alunos para o complexo existente no mundo, sendo tais práticas meios eficazes na construção de cidadãos mais críticos e autônomos.

\section{REFERÊNCIAS}

BARDIN, L. Análise de conteúdo, 3. Ed. Lisboa: Edições 70, 2004.

CHASSOT, Atico. Alfabetização científica: uma possibilidade para a inclusão social. Revista Brasileira de Educação. Jan/Fev/Mar/Abr, número 22, 2003.

DELIZOICOV, D, et al. Ensino de ciências: fundamentos e métodos. 4. Ed. São Paulo: Cortez, 2011.

DELIZOICOV, Demétrio; ANGOTTI, José André P. Física. São Paulo: Cortez, 1992. 
DURANT, John. o que é alfabetização científica. In: MASSARANI, Luisa; TURNEY, Jon; MOREIRA, Ildeu de Castro (Org.). Terra incógnita: a interface entre ciência e público. Rio de Janeiro: Vieira \& Lent, 2005. p. 13-26.

FREIRE, Paulo. Pedagogia da Autonomia. São Paulo: Paz e Terra, 1996.

MORIN, Edgar. Silva, Catarina Eleonora (Trad). Os sete saberes necessários à educação do futuro. 6. ed. São Paulo: Cortez; Brasília, DF: UNESCO, 2002.

TEIXEIRA, P.M.M.. A Educação Científica sob a perspectiva da Pedagogia Histórico-Crítica e do movimento CTS no ensino de ciências. Revista Ciência e Educação, vol.9, n.2, 2003, p.177-190. 